Fetal Diagnosis and Therapy
Fetal Diagn Ther 2019;46:217-222

DOI: $10.1159 / 000494055$
Received: June 14, 2018

Accepted after revision: September 25, 2018

Published online: November 22, 2018

\title{
Screening for Common Fetal Trisomies in Twin Pregnancies: First-Trimester Combined, Cell-Free DNA, or Both?
}

\author{
Lucia Pasquini $^{a} \quad$ Ilaria Ponziani $^{\mathrm{a}}$ Enrico Periti ${ }^{\mathrm{b}}$ Laura Marchi $^{\mathrm{a}}$ Carlo Luchi $^{\mathrm{c}}$ \\ Veronica Accurti ${ }^{d}$ Francesco D'Ambrosi $^{d}$ Nicola Persico $^{d, e}$ \\ ${ }^{a}$ Fetal Medicine Unit, Department of Woman and Child Health, Careggi University Hospital, Florence, Italy; \\ bUnità Funzionale Territoriale, Piero Palagi Hospital, Azienda USL Toscana Centro, Florence, Italy; \\ 'Department of Obstetrics and Gynecology, University of Pisa, Pisa, Italy; ${ }^{\mathrm{d}}$ Department of Obstetrics \\ and Gynecology "L. Mangiagalli," Fondazione Ca' Granda Ospedale Maggiore Policlinico, Milan, Italy; \\ eDepartment of Clinical Science and Community Health, University of Milan, Milan, Italy
}

\section{Keywords}

Combined test · Cell-free DNA · Twin pregnancies .

First-trimester screening $\cdot$ Chromosomal abnormalities

\begin{abstract}
Objective: To examine the distribution of risks for fetal trisomies after first-trimester combined screening in twins and to investigate different strategies for clinical implementation of cell-free DNA (cfDNA) testing. Methods: We retrospectively analyzed all twin pregnancies undergoing first-trimester combined screening over a 10 years' period. The population was stratified according to various risk cut-offs, and we examined different screening strategies for implementation of cfDNA testing in terms of impact on invasive testing rate, cfDNA test failure rate, and economic costs. Results: We included 572 twin pregnancies: 480 (83.92\%) dichorionic and $92(16.08 \%)$ monochorionic. Performing a first-line combined screening and offering cfDNA testing to the group with a risk between 1 in 10 and 1 in 1,000, would lead to an invasive testing rate of $2.45 \%$, and cfDNA testing would be performed in $22.20 \%$ of the population. This strategy would be cost-neutral compared to universal combined screening
\end{abstract}

alone. Conclusions: First-trimester combined screening results can be used to stratify twin pregnancies into different risk categories and select those that could be offered cfDNA testing. A contingent screening strategy would substantially decrease the need for invasive testing in twins and it would be cost-neutral compared to combined testing alone.

(c) 2018 S. Karger AG, Basel

\section{Introduction}

The combination of maternal age, fetal nuchal translucency (NT) thickness, maternal serum free $\beta$-human chorionic gonadotropin, and pregnancy-associated plasma protein A in the first trimester of pregnancy is a wellestablished method of screening for trisomies in singleton gestations with reported detection rates (DR) of 90 , 97 , and $92 \%$ for trisomy 21,18 , and 13 , for an overall falsepositive rate (FPR) of $4 \%$ [1]. Combined test (CT) in twin pregnancies has been evaluated in few studies [2-4], and a recent meta-analysis showed that the performance is similar to singletons, with a DR for trisomy 21 of $89.3 \%$ and an FPR of 5.4\% [5].

\section{KARGER}

(c) 2018 S. Karger AG, Basel

E-Mail karger@karger.com

www.karger.com/fdt
Lucia Pasquini

Fetal Medicine Unit, Department of Woman and Child Health

Careggi University Hospital, Largo Brambilla, 3

IT-50134 Florence (Italy)

E-Mail luciapasquini@tin.it 
Cell-free DNA (cfDNA) testing in maternal blood has been recently introduced as a new method of screening for trisomies 21,18 , and 13 , and the published studies on singleton pregnancies have consistently reported DR in the range of $99 \%$ or more, with an FPR of $0.1-0.3 \%$ and a test failure rate of $0.9-4.9 \%$ [6-9]. Different strategies for clinical implementation of cfDNA testing in singleton pregnancies, as universal screening or contingent to the results of the CT, are currently under investigation [10-12]. Few studies have examined the performance of cfDNA testing in twin pregnancies, and the preliminary results showed similar DR and FPR compared to singletons [7, 13-15]. However, the reported test failure rate after the first blood sample appears to be higher than in singletons, with a potential impact on the overall performance of screening, but there is a wide variation from 2.9 to $9.4 \%$ among the few published studies [13-15]. In addition, the ultrasound component of the $\mathrm{CT}$ is essential to determine chorionicity and to identify structural defects detectable in the first trimester, with major clinical implications for subsequent management $[16,17]$. Therefore, investigation into possible ways for implementation of CT and cfDNA testing together is important to maximize DR and to minimize invasive testing rate in screening for common trisomies, retaining the ability to obtain the additional clinical information provided by the CT.

The aim of this study was to examine the distribution of risks after first-trimester $\mathrm{CT}$ in twin pregnancies and to investigate different strategies for clinical implementation of cfDNA testing.

\section{Methods}

This retrospective, multicenter study included twin pregnancies that underwent first-trimester combined screening between March 2005 and September 2015 at three Italian Fetal Medicine Centers (Careggi University Hospital, Florence; Piero Palagi Hospital, Florence; Pisa University Hospital, Pisa). Written consent was obtained from all patients participating in the study.

Screening was based on the combination of maternal age, NT thickness measured between $11^{+0}$ and $13^{+6}$ weeks, and maternal serum free $\beta$-human chorionic gonadotropin and pregnancy-associated plasma protein A measurements between $9^{+0}$ and $13^{+6}$ weeks. Chorionicity was determined by ultrasound demonstrating the lambda or T sign. Pregnancy dating was based on the crownrump length of the larger twin. Ultrasound scans were carried out by trained sonographers accredited by the Fetal Medicine Foundation (FMF London, UK; www.fetalmedicine.org [18]). The biochemical markers were analyzed using DELFIA ${ }^{\circledR}$ Xpress system (Perkin Elmer, Waltham, MA, USA) or Kryptor analyzer (BRAHAMS $^{\circledR}$ AG, Berlin, Germany). Ultrasound and laboratory data
Table 1. Maternal and pregnancy characteristics of the population of 572 twin pregnancies

\begin{tabular}{lc}
\hline Maternal age, years & $35(32-38)$ \\
Maternal weight, kg & $61(55-68)$ \\
ART conception & $268(46.85)$ \\
Ethnicity & \\
$\quad$ White & $558(97.55)$ \\
$\quad$ African & $8(1.39)$ \\
$\quad$ East Asian & $2(0.35)$ \\
$\quad$ South Asian & $2(0.35)$ \\
$\quad$ Mixed & $2(0.35)$ \\
Smokers & $57(9.96)$ \\
Gestational age at ultrasound, days & $85(83-87)$ \\
CRL, mm & $57.40(53.20-62.00)$ \\
NT, mm & $1.60(1.37-1.89)$ \\
Chorionicity & \\
Dichorionic & $480(83.92)$ \\
$\quad$ Monochorionic & $92(16.08)$ \\
\end{tabular}

Data are presented as $n(\%)$ or median (interquartile range); ART, assisted reproductive technology; CRL, crown rump length; NT, nuchal translucency.

were entered into the FMF software to calculate the estimated risk for trisomies 21, 18, and 13. For dichorionic twins, the individual risk for each fetus was considered, whereas for monochorionic twins an overall pregnancy risk was calculated based on the average of the risks of the two fetuses.

The test was considered positive if the risk was $\geq 1: 250$, and all patients with a positive result for at least one twin were offered invasive testing as per local clinical guidelines. Fetal karyotyping was carried out by chorionic villous sampling (CVS) or amniocentesis. For patients who did not undergo invasive testing, neonatal outcome and information on clinical phenotype were obtained from computerized medical records or by telephone interviews.

The dataset was analyzed examining firstly the distribution of the entire cohort of pregnancies, according to their risk after combined screening. Subsequently, different intermediate risk groups were identified based on various risk cut-off ranges. The impact of different screening strategies in terms of invasive testing rate, cfDNA test failure rate, and economic costs was evaluated. The invasive testing rates of combined screening were calculated based on predefined risk cut-offs. The number of invasive procedures following a high-risk result from cfDNA testing was calculated assuming that the test would have detected all cases of trisomy 21, 18 , and 13 with no false-positive results. cfDNA test failure rate was calculated as the mean of the published test failure rates after the first blood sample in twin pregnancies (5\%) [13-15]. In case of cfDNA test failure, it was assumed to offer a second testing to every patient, considering to obtain a result after the second test in 50\% of cases, as the mean of published data [13-15]. The economic costs were calculated based on regional public health reimbursements as follows: NT scan = EUR 51; maternal biochemistry = EUR 32; CVS or amniocentesis with genetic analysis = EUR 465 (1 sample) for monochorionic and EUR 894 (2 samples) for dichorionic twins; cfDNA test (inclusive of laboratory and clinical workflow) $=$ EUR 347 . 
Table 2. Distribution of twin pregnancies with different fetal karyotypes according to the highest combined risk and NT thickness within each twin pair in the study population of 572 twin pregnancies

\begin{tabular}{lcllll}
\hline $\begin{array}{l}\text { Risk cut-off } \\
\text { Total }(n=572)\end{array}$ & $\begin{array}{l}\text { Normal } \\
(n=567)\end{array}$ & $\begin{array}{l}\text { Trisomy } 21 \\
(n=2)\end{array}$ & $\begin{array}{l}\text { Trisomy } 18 \\
(n=1)\end{array}$ & $\begin{array}{l}\text { Trisomy } 13 \\
(n=1)\end{array}$ & $\begin{array}{l}\text { Other aneuploidies } \\
(n=1)\end{array}$ \\
\hline 1 in 10 & $3(0.53 \%)$ & 0 & 0 & 0 & 0 \\
1 in 20 & $10(1.76 \%)$ & 0 & 0 & 0 & 0 \\
1 in 30 & $15(2.66 \%)$ & 0 & $1(100 \%)$ & $1(100 \%)$ & 0 \\
1 in 40 & $24(4.23 \%)$ & $1(50 \%)$ & $1(100 \%)$ & $1(100 \%)$ & 0 \\
1 in 50 & $30(5.29 \%)$ & $1(50 \%)$ & $1(100 \%)$ & $1(100 \%)$ & 0 \\
1 in 100 & $38(6.70 \%)$ & $1(50 \%)$ & $1(100 \%)$ & $1(100 \%)$ & $1(100 \%)$ \\
1 in 250 & $62(10.93 \%)$ & $2(100 \%)$ & $1(100 \%)$ & $1(100 \%)$ & $1(100 \%)$ \\
1 in 500 & $81(14.23 \%)$ & $2(100 \%)$ & $1(100 \%)$ & $1(100 \%)$ & $1(100 \%)$ \\
1 in 1,000 & $125(22.05 \%)$ & $2(100 \%)$ & $1(100 \%)$ & $1(100 \%)$ & $1(100 \%)$ \\
1 in 1,500 & $169(29.81 \%)$ & $2(100 \%)$ & $1(100 \%)$ & $1(100 \%)$ & $1(100 \%)$ \\
1 in 2,000 & $211(37.21 \%)$ & $2(100 \%)$ & $1(100 \%)$ & $1(100 \%)$ & $1(100 \%)$ \\
1 in 2,500 & $239(42.15 \%)$ & $2(100 \%)$ & $1(100 \%)$ & $1(100 \%)$ & $1(100 \%)$ \\
1 in 3,000 & $267(47.09 \%)$ & $2(100 \%)$ & $1(100 \%)$ & $1(100 \%)$ & $1(100 \%)$ \\
\hline Nuchal translucency & & & & & 0 \\
$\geq 4.0$ mm & $5(0.88 \%)$ & $1(50 \%)$ & $1(100 \%)$ & 0 & $1(100 \%)$ \\
$\geq 3.5$ mm & $6(1.06 \%)$ & $1(50 \%)$ & $1(100 \%)$ & $1(100 \%)$ \\
\hline
\end{tabular}

Statistical analysis was performed using SPSS version 23.0 (SPSS Inc., Chicago, IL, USA) and Microsoft Office Excel (Microsoft Corp., Redmond, WA, USA). Data regarding continuous variables were expressed as median and interquartile range (IQR); categorical variables were expressed as number and percentages.

\section{Results}

The study population consisted of 572 twin pregnancies (1,144 fetuses) that underwent first-trimester screening. Table 1 summarizes maternal and pregnancy characteristics of the study population. The median maternal age was 35 years (IQR 32-38 years) and the median gestational age at ultrasound was 12.14 (IQR 11.85-12.43) weeks. In 268 $(46.85 \%)$ cases, the pregnancy was obtained through assisted reproductive techniques. There were 480 (83.92\%) dichorionic and $92(16.08 \%)$ monochorionic pregnancies. Fetal karyotype and/or neonatal phenotype was normal in $1,139(99.56 \%)$ cases and abnormal in the remaining 5 (0.44\%). The abnormal group included 5 fetuses, each from a different dichorionic pregnancy, two with trisomy 21 and one case each of trisomy 18 , trisomy 13 , and $47 \mathrm{XY}+8 / 46 \mathrm{XY}$ mosaicism (diagnosed at CVS and confirmed by amniocentesis). In all chromosomally abnormal cases, the risk for trisomy 21,18 , or 13 after combined screening was $\geq 1$ in 250 . No additional cases of aneuploidies were found on postnatal follow-up in cases with a risk $<1$ in 250 .

First-Trimester Contingent Screening in Twins
Table 2 shows the distribution of pregnancies with different fetal karyotypes according to the highest combined risk and NT thickness within each twin pair. In Table 3, we reported the proportion of pregnancies included between an upper and a lower risk cut-off, defining various intermediate risk groups that could be offered cfDNA testing. Subsequently, we examined different screening strategies with the associated invasive testing rate, cfDNA test failure rates, and economic costs (Table 4). The strategy of performing a first-line combined screening, offering cfDNA testing to the group of pregnancies with a risk between 1 in 10 and 1 in 1,000, would require that an invasive diagnostic procedure is carried out in $2.45 \%$ of the cases and that cfDNA testing is offered to $22.20 \%$ of the population. This strategy would be cost-neutral compared to universal combined screening alone. In addition, the overall cfDNA test failure rate would be lower compared to universal cfDNA screening ( 1.05 vs. $5.1 \%$, respectively; $p<0.05$ ) because the test would be offered to a smaller proportion of the population.

\section{Discussion}

The main findings of this study are that firstly combined screening results can be used to stratify the population of twin pregnancies into different risk categories, to 
Table 3. Distribution of pregnancies in the study population according to an upper and lower risk cut-off after combined screening, defining different intermediate-risk groups that could be offered cfDNA testing in a contingent strategy

\begin{tabular}{|c|c|c|c|c|c|c|}
\hline \multirow[b]{2}{*}{ Upper risk cut-off } & \multicolumn{6}{|c|}{ Lower risk cut-off } \\
\hline & 1 in 500 & 1 in 1,000 & 1 in 1,500 & 1 in 2,000 & 1 in 2,500 & 1 in 3,000 \\
\hline 1 in 10 & $83(14.51 \%)$ & $127(22.20 \%)$ & $171(29.90 \%)$ & $213(37.24 \%)$ & $241(42.13 \%)$ & $269(47.03 \%)$ \\
\hline 1 in 30 & $69(12.06 \%)$ & $113(19.76 \%)$ & $157(27.45 \%)$ & $199(34.79 \%)$ & $227(39.69 \%)$ & $255(44.58 \%)$ \\
\hline 1 in 40 & $59(10.31 \%)$ & $103(18.01 \%)$ & 147 (25.70\%) & $189(33.04 \%)$ & 217 (37.94\%) & $245(42.83 \%)$ \\
\hline 1 in 50 & $53(9.27 \%)$ & $97(16.96 \%)$ & $141(24.65 \%)$ & $183(31.99 \%)$ & $211(36.89 \%)$ & $239(41.78 \%)$ \\
\hline 1 in 250 & $19(3.32 \%)$ & $63(11.01 \%)$ & $107(18.71 \%)$ & $149(26.05 \%)$ & 177 (30.94\%) & $205(35.84 \%)$ \\
\hline
\end{tabular}

Data are presented as $n(\%)$.

Table 4. Impact of different screening strategies on cfDNA failure rates, invasive testing rates, and economic costs based on our population of 572 twin pregnancies

\begin{tabular}{|c|c|c|c|c|c|}
\hline Strategy & Indication for invasive testing & cfDNA test & $\begin{array}{l}\text { cfDNA test } \\
\text { failure }\end{array}$ & Invasive test & Cost, EUR \\
\hline Universal combined test & Risk $\geq 1$ in 250 & - & - & $67(11.71 \%)$ & 104.800 \\
\hline Universal cfDNA test & $\begin{array}{l}\text { cfDNA high risk result or no } \\
\text { result after } 2 \text { cfDNA tests }\end{array}$ & $572(100 \%)$ & $29(5.10 \%)$ & $18(3.15 \%)$ & 223.781 \\
\hline Universal ultrasound + cfDNA test & $\begin{array}{l}\mathrm{NT}>3.5 \mathrm{~mm} \text { and/or cfDNA high } \\
\text { risk result or no result after } 2 \\
\text { cfDNA tests }\end{array}$ & $572(100 \%)$ & $29(5.10 \%)$ & $25(4.37 \%)$ & 249.773 \\
\hline $\begin{array}{l}\text { Universal combined test and cfDNA } \\
\text { test if the risk is between } 1 \text { in } 10 \\
\text { and } 1 \text { in } 1,000\end{array}$ & $\begin{array}{l}\text { Combined risk }>1 \text { in } 10 \text { and/or } \\
\mathrm{NT}>3.5 \mathrm{~mm} \text { and/or cfDNA high } \\
\text { risk result or combined risk } \geq 1 \text { in } \\
250 \text { and no result at cfDNA }\end{array}$ & $127(22.20 \%)$ & $6(1.05 \%)$ & $14(2.45 \%)$ & 102.774 \\
\hline
\end{tabular}

select those that could be offered cfDNA testing. Secondly, a contingent screening strategy would substantially decrease the need for invasive testing in twins and it would be cost-neutral compared to combined testing alone.

It is generally agreed that every pregnant woman should be offered an ultrasound examination in the first trimester of pregnancy [19]. The 11-13 weeks' scan has become part of routine obstetric care because it can identify about half of the cases with major structural abnormalities and all of those with increased NT thickness, which are established clinical risk factors for adverse fetal outcome $[17,19]$. In twin pregnancies, ultrasound is particularly important because it allows to determine chorionicity, with major implications on pregnancy follow-up and outcome [16]. The inclusion of maternal serum biochemistry, with appropriate adjustments for dichorionic and monochorionic twin pregnancies, provides a more accurate risk assessment for major trisomies compared to NT thickness alone [5].

A major advantage of cfDNA testing is that it is associated with a very low FPR of about $0.3 \%$ if the test is used only in screening for trisomies 21, 18, and 13 [7]. However, it does not detect all the possible chromosomal abnormalities; for example, the case of $47 \mathrm{XY}+8 / 46 \mathrm{XY}$ mosaicism present in this study would not have been detected using cfDNA testing only [7]. Moreover, cfDNA analysis does not provide any information on fetal structural development, and the results should always be interpreted in combination with ultrasound findings. For example, if a major structural defect or a very large NT (typically $\geq 3.5 \mathrm{~mm}$ ) is detected by ultrasound, the option of invasive testing should be discussed irrespective of the results of cfDNA analysis [17]. In addition, the few published studies on cfDNA testing in twin pregnancies showed a higher test failure rate compared 
to singletons [13-15] and the test is still expensive at the time of writing, with a local cost of about EUR 350 inclusive of laboratory and counselling workflow. These clinical and economic considerations do not support the use of cfDNA testing as a stand-alone universal screening method.

Our data showed that first-trimester combined screening can be used to identify subgroups of the population of twin pregnancies based on the calculated patient-specific risk for common trisomies. Different cut-off ranges can be used to define the intermediate risk group that could be offered cfDNA testing (Table 3 ). In the estimation of the performance of the different screening strategies, a minimum invasive testing rate should always be set based on established clinical criteria that define the very-high-risk group, such as a combined risk $\geq 1$ in 10 , $\mathrm{NT} \geq 3.5 \mathrm{~mm}$ and/or other major ultrasound anomalies. Based on our data, the strategy of offering cfDNA testing to patients with a risk between 1 in 10 and 1 in 1,000 after combined screening would produce a significant reduction in the invasive testing rate ( 11.71 vs. $2.45 \%)$. In this strategy, it was considered to offer an invasive procedure to patients with no results at cfDNA testing only if the CT was positive (risk $\geq 1: 250$ ) for at least one twin. The implementation of cfDNA testing contingent to the results of combined screening has been shown to be effective in reducing the invasive testing rate in singleton pregnancies $[11,12,20]$. In addition, a recent study showed that the results of combined screening are useful in the clinical management of cases with a cfDNA test failure [21].

Economic budget analysis in the field of prenatal screening should take into account the costs of the different required technologies and equipment (i.e., ultrasound machines, biochemical instruments, DNA sequencers, needles, culture media, etc.), as well as the costs needed to run the service, such as personnel hours needed to perform the different analyses and to provide appropriate parents' counselling. In Italy, these costs are established at a regional level by the local healthcare authorities. In our population, contingent screening with cfDNA testing to the 1 in 10-1 in 1,000 risk group would be cost-neutral compared with combined screening alone, because the additional costs for cfDNA testing would be counterbalanced by the reduction in costs of invasive testing. In addition, the overall cfDNA test failure rate would be lower compared to universal cfDNA screening because the test would be offered to a smaller proportion of the population. A screening strategy based on universal cfDNA screening alone or in combination

with ultrasound would double the costs compared to contingent screening, with a similar number of invasive procedures (Table 4).

A strength of this study is that we examined a large cohort of twin pregnancies undergoing first-trimester combined screening to assess both clinical and economic implications of the different screening strategies. The main limitations are the small number of fetuses with chromosomal abnormalities and the lack of information on cfDNA testing results. Therefore, our data cannot be used to examine differences in the DR for common trisomies between the different strategies, and future larger studies are required to investigate this aspect further.

From a clinical perspective, our results can be useful to clinicians, hospitals, and health authorities to select the preferred strategy in screening for aneuploidies in twin pregnancies, according to service availability and economic resources.

\section{Statement of Ethics}

Written consent was obtained from all patients participating in the study. Ethics committee approval was not considered to be necessary as we only used fully anonymized clinical data and a hypothetical cohort.

\section{Disclosure Statement}

The authors have no conflict of interest to declare.

References

Fetal Diagn Ther 2019;46:217-222 DOI: $10.1159 / 000494055$
1 Santorum M, Wright D, Syngelaki A, Karagioti N, Nicolaides KH. Accuracy of first-trimester combined test in screening for trisomies 21, 18 and 13. Ultrasound Obstet Gynecol. 2017 Jun;49(6):714-20.

2 Prats P, Rodríguez I, Comas C, Puerto B. First trimester risk assessment for trisomy 21 in twin pregnancies combining nuchal translucency and first trimester biochemical markers. Prenat Diagn. 2012 Oct;32(10):927-32.

3 Spencer K, Nicolaides KH. Screening for trisomy 21 in twins using first trimester ultrasound and maternal serum biochemistry in a one-stop clinic: a review of three years experience. BJOG. 2003 Mar;110(3):276-80.

4 Madsen HN, Ball S, Wright D, Tørring N, Petersen $\mathrm{OB}$, Nicolaides $\mathrm{KH}$, et al. A reassessment of biochemical marker distributions in trisomy 21-affected and unaffected twin pregnancies in the first trimester. Ultrasound $\mathrm{Ob}$ stet Gynecol. 2011 Jan;37(1):38-47. 
5 Prats P, Rodríguez I, Comas C, Puerto B. Systematic review of screening for trisomy 21 in twin pregnancies in first trimester combining nuchal translucency and biochemical markers: a meta-analysis. Prenat Diagn. 2014 Nov; 34(11):1077-83.

6 Quezada MS, Gil MM, Francisco C, Oròsz G, Nicolaides KH. Screening for trisomies 21, 18 and 13 by cell-free DNA analysis of maternal blood at 10-11 weeks' gestation and the combined test at 11-13 weeks. Ultrasound Obstet Gynecol. 2015 Jan;45(1):36-41.

7 Gil MM, Accurti V, Santacruz B, Plana MN, Nicolaides KH. Analysis of cell-free DNA in maternal blood in screening for aneuploidies: updated meta-analysis. Ultrasound Obstet Gynecol. 2017 Sep;50(3):302-14.

8 Nicolaides KH, Syngelaki A, Ashoor G, Birdir C, Touzet G. Noninvasive prenatal testing for fetal trisomies in a routinely screened firsttrimester population. Am J Obstet Gynecol 2012;207(5):374.e1-6.

9 Bianchi DW, Parker RL, Wentworth J, Madankumar R, Saffer C, Das AF, et al.; CARE Study Group. DNA sequencing versus standard prenatal aneuploidy screening. N Engl J Med. 2014 Feb;370(9):799-808.

10 Syngelaki A, Pergament E, Homfray T, Akolekar R, Nicolaides KH. Replacing the combined test by cell-free DNA testing in screening for trisomies 21, 18 and 13: impact on the diagnosis of other chromosomal abnormalities. Fetal Diagn Ther. 2014;35(3):174-84.
11 Gil MM, Revello R, Poon LC, Akolekar R, Nicolaides KH. Clinical implementation of routine screening for fetal trisomies in the UK NHS: cell-free DNA test contingent on results from first-trimester combined test. Ultrasound Obstet Gynecol. 2016 Jan;47(1):45-52.

12 Nicolaides KH, Wright D, Poon LC, Syngelaki A, Gil MM. First-trimester contingent screening for trisomy 21 by biomarkers and maternal blood cell-free DNA testing. Ultrasound Obstet Gynecol. 2013 Jul;42(1):41-50

13 Bevilacqua E, Gil MM, Nicolaides KH, Ordoñez E, Cirigliano V, Dierickx H, et al. Performance of screening for aneuploidies by cell-free DNA analysis of maternal blood in twin pregnancies. Ultrasound Obstet Gynecol. 2015 Jan;45(1):61-6.

14 Le Conte G, Letourneau A, Jani J, Kleinfinger P, Lohmann L, Costa JM, et al. Cell-free fetal DNA analysis in maternal plasma as a screening test for trisomies 21,18 and 13 in twin pregnancies. Ultrasound Obstet Gynecol. 2018 Sep;52(3):318-324.

15 Sarno L, Revello R, Hanson E, Akolekar R, Nicolaides $\mathrm{KH}$. Prospective first-trimester screening for trisomies by cell-free DNA testing of maternal blood in twin pregnancy. Ultrasound Obstet Gynecol. 2016 Jun;47(6): 705-11.
16 Khalil A, Rodgers M, Baschat A, Bhide A, Gratacos E, Hecher K, et al. ISUOG Practice Guidelines: role of ultrasound in twin pregnancy. Ultrasound Obstet Gynecol. 2016 Feb; 47(2):247-63.

17 Salomon LJ, Alfirevic Z, Audibert F, Kagan KO, Paladini D, Yeo G, et al.; ISUOG Clinical Standards Committee. ISUOG updated consensus statement on the impact of cfDNA aneuploidy testing on screening policies and prenatal ultrasound practice. Ultrasound $\mathrm{Ob}$ stet Gynecol. 2017 Jun;49(6):815-6.

18 The Fetal Medicine Foundation. http://www. fetalmedicine.org/ [Accessed 31 May 2018]

19 Salomon LJ, Alfirevic Z, Bilardo CM, Chalouhi GE, Ghi T, Kagan KO, et al. ISUOG practice guidelines: performance of first-trimester fetal ultrasound scan. Ultrasound $\mathrm{Ob}$ stet Gynecol. 2013 Jan;41(1):102-13.

20 Persico N, Boito S, Ischia B, Cordisco A, De Robertis V, Fabietti I, et al. Cell-free DNA testing in the maternal blood in high-risk pregnancies after first-trimester combined screening. Prenat Diagn. 2016 Mar;36(3): 232-6.

21 Revello R, Sarno L, Ispas A, Akolekar R, Nicolaides KH. Screening for trisomies by cell-free DNA testing of maternal blood: consequences of a failed result. Ultrasound Obstet Gynecol. 2016 Jun;47(6):698-704. 